\title{
Mechanical and Abrasive Wear Behavior of Metal Sulphide Lubricant Filled Epoxy Composites
}

\author{
M. Sudheer, N. Karthik Madhyastha, M. Kewin Amanna, \\ B. Jonthan, and K. Mayur Jayaprakash \\ Department of Mechanical Engineering, St. Joseph Engineering College, Mangalore, Karnataka State 575028, India \\ Correspondence should be addressed to M. Sudheer; msudheerm2002@yahoo.co.in
}

Received 22 April 2013; Accepted 13 May 2013

Academic Editors: T. R. Chantara, Y. Chen, and J. I. Velasco

Copyright (c) 2013 M. Sudheer et al. This is an open access article distributed under the Creative Commons Attribution License, which permits unrestricted use, distribution, and reproduction in any medium, provided the original work is properly cited.

\begin{abstract}
The present work reveals the effect of the addition of commercial $\mathrm{MoS}_{2}(10 \mathrm{wt} \%)$ particles on mechanical and two-body abrasive wear behavior of epoxy with/without glass fiber mat reinforcement. The composites were fabricated using casting and simple hand lay-up techniques followed by compression molding. The mechanical properties such as density, hardness, tensile, and flexural properties were determined as per ASTM standards. The abrasive wear testing was carried out using pin-on-disc wear tester for different loads and abrading distances at constant speed of $1 \mathrm{~m} / \mathrm{s}$. A significant reduction in wear loss and specific wear rate was noticed after the incorporation of $\mathrm{MoS}_{2}$ filler allowing less wear of matrix during abrasion which in turn facilitated lower fiber damage. However the incorporation of $\mathrm{MoS}_{2}$ particles had a detrimental effect on most of the mechanical properties of the composites. The worn surface features were investigated through scanning electron microscopy (SEM) in order to investigate the wear mechanisms.
\end{abstract}

\section{Introduction}

In recent times, there has been a remarkable growth in largescale production of fiber and/or filler-reinforced polymer matrix composites for engineering applications [1]. Among various types of fiber reinforcements, namely, short, long (unidirectionally reinforced UD composites), fabric (bidirectionally reinforced $\mathrm{BD}$ composites), and the combinations of fabrics or long fibers in various directions (multidirectionally reinforced), BD reinforcement offers a unique solution to ever increasing demands on advanced materials in terms of better performance and ease in processing. Thermoset epoxy resins are extensively studied as a matrix material as they exhibits low shrinkage, higher mechanical properties, easy fabrication, excellent chemical and moisture resistance, good wettability, and good electrical characteristics [2].

One of the well-known reinforcement for polymers is glass fibers. Glass fibers have very high strength and high stiffness. It has been found that size and volume fraction of the fibers/fillers play an important role to improve the mechanical properties such as stiffness and strength. Polymer composites are extensively used in the tribosituations where resistance to abrasive wear is an extremely important criterion. Typical examples are chute liners, conveyor aids, vanes, gears, for pumps handling industrial fluids, sewage and abrasive contaminated water, and so forth. [3]. Polymers filled with solid lubricant (SL) have been extensively studied because of the increasing industrial and material applications. Several researchers [4-14] have revealed variation in properties of polymer composites filled with solid lubricants such as graphite, molybdenum disulphide $\left(\mathrm{MoS}_{2}\right)$, and polytetrafluoroethylene (PTFE).

Pettarin et al. [4] have assessed the effect of the addition of commercial molybdenum disulphide $\left(\mathrm{MoS}_{2}\right)$ on the tribological behavior of high molecular weight high density polyethylene and observed that addition of $10 \mathrm{wt} \%$ of solid lubricant $\left(\mathrm{MoS}_{2}\right)$ increased the wear resistance under both sliding and abrasive wear conditions, but with a high cost in its mechanical behaviour. A comprehensive comparative study of four different internal lubricants (PTFE, graphite, $\mathrm{MoS}_{2}$, and $\mathrm{SnS}_{2}$ ) on sliding wear of epoxy compounds was reported by Jacobs et al. [5]. They observed that only PTFE was beneficial which reduced the specific wear rate by a factor ranging from 10 to 100 . In another comparative 


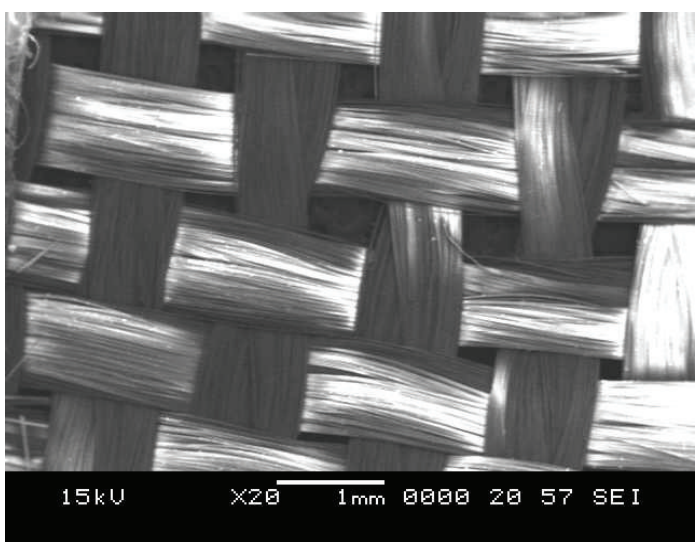

(a)

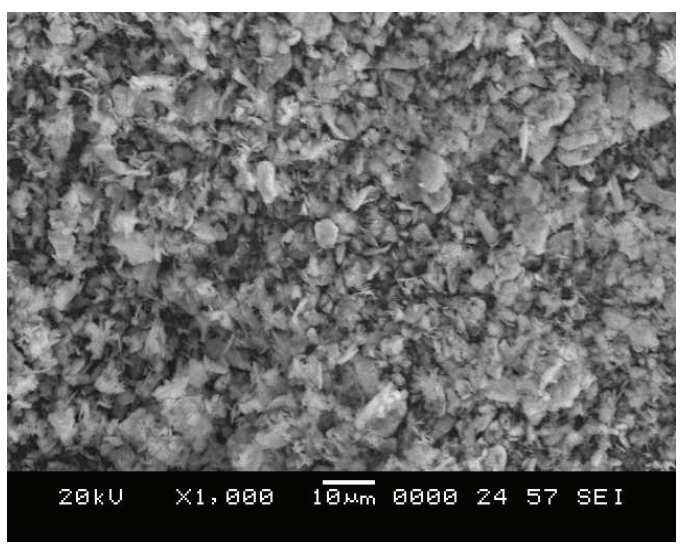

(b)

FIGURE 1: SEM pictures of (a) glass fibers and (b) $\mathrm{MoS}_{2}$ particles.

study between graphite and PTFE as solid lubricants with poly phthalazinone ether sulfone ketone (PPESK), Zhang et al. [6] observed that 5-25 wt\% of PTFE and 5-30 wt\% of graphite contribute to the improved tribological performance of PPESK at room temperature. It was also observed that PTFE-filled PPESK composites showed much smoother surfaces than same concentration composites filled by graphite. Li et al. [7] demonstrated the combined effect of using two solid lubricants (Graphite and $\mathrm{MoS}_{2}$ ) for improving the triboperformance of polymer composites.

Many researchers [8-13] have proposed that solid lubricant alone will not improve the tribo-performance of neat polymer and along with fiber reinforcement will have beneficiary effect on the performance of composites. Zhang et al. [8] observed that small incorporation of $\mathrm{MoS}_{2}$ was harmful to the improvement of friction and wear behaviors of the carbon fiber-reinforced polyimide composites. In their study, reduction in friction coefficient was observed at above $5 \mathrm{wt} \% \mathrm{MoS}_{2}$, and decrease in wear rate observed was at above 10 wt $\% \mathrm{MoS}_{2}$.

A comparative performance of glass-epoxy composites, having graphite of two different levels (2.5 and $4.5 \mathrm{wt} \%$ ), was reported by Kishore et al. [9]. In their study, a lower coefficient of friction and lesser wear for any combination of load and velocity was observed for higher graphite (4.5 wt \%) bearing composite. Improvement in tribo-performance of glass-epoxy composites with graphite as a filler was also reported by Suresha et al. [10] in their recent studies.

Wang et al. [11] observed that wear and friction reduction were more significant while the carbon fiber was used as reinforcement along with $\mathrm{MoS}_{2}$ filler in case of nylon 1010 composites. It was mentioned that the ability of the synergistic fillers in helping the formation of thin, uniform, and continuous transfer film would contribute to the increase in wear resistance of nylon composites. Bijwe et al. [12] reported that glass fiber reinforcement (18\%) along with solid lubricants (PTFE and $\mathrm{MoS}_{2}, 2 \%$ ) enhanced the wear performance of polyethersulfone by an order of two. In case of solid lubricants, PTFE was reported to be more beneficial than $\mathrm{MoS}_{2}$. Zhang et al. [13] noticed that combinative addition of graphite (10\%), short carbon fiber (10\%), and micro $\mathrm{SiO}_{2}(3 \%)$ was most effective in improving the friction-reducing and antiwear abilities of polyetherimide composites. Important observation made was that single incorporation of micro $\mathrm{SiO}_{2}$ was harmful to the improvement of friction and wear behavior of polyetherimide composites. These results indicate that wear-reduction action of fiber/fillers is specific to the polymer-filler pair. However, development of the composites based on solid lubricants with enhanced tribological properties often conflicts with the coinciding achievement of superior mechanical strength. As a consequence, it is necessary to study not only the wear behavior, but also, mechanical performance of the composites.

Keeping this in view, the present work aims at investigating mechanical and tribological properties of $\mathrm{MoS}_{2}$ particulate filled epoxy and glass-epoxy composites. Mechanical properties were evaluated under identical test conditions. Here, abrasive wear test was performed under constant sliding velocity and for different sliding distances and normal loads. This study helps in understanding the effect of lubricating filler $\left(\mathrm{MoS}_{2}\right)$ on neat epoxy and glass-epoxy composites.

\section{Experimental Details}

2.1. Materials. Composites were fabricated using epoxy resin (Araldite LY556) and hardener (HY951) supplied by M/s. Hindustan Ciba Geigy Ltd., Mumbai, India. Molybdenum disulphide $\left(\mathrm{MoS}_{2}\right)$ particles $(3-4 \mu \mathrm{m})$ obtained from M/s. Tribocor Technologies, Mysore, India, were used as solid lubricant. Bidirectional plain-woven E-glass fabrics (610 GSM) used as reinforcement in the case of laminates were supplied by $\mathrm{M} / \mathrm{s}$. Suntech Fiber Ltd., Bengaluru, India. SEM images of glass fibers and solid lubricant particles are presented in Figure 1.

2.2. Fabrication of Composites. Two methods were used for fabrication of the composites, namely, resin casting and hand lay-up technique.

2.2.1. Resin Casting Method. The $\mathrm{MoS}_{2}$ fillers were preheated to $80^{\circ} \mathrm{C}$ for $2 \mathrm{hrs}$ in a hot air oven to remove any moisture 
TABLE 1: Formulation of composite samples.

\begin{tabular}{|c|c|c|c|}
\hline Sample code & Matrix & Reinforcement & Filler \\
\hline EP & Epoxy & - & - \\
\hline $\mathrm{EP}+\mathrm{SL}$ & $\begin{array}{l}\text { Epoxy } \\
\text { (90 wt\%) }\end{array}$ & - & $\mathrm{MoS}_{2}(10 \mathrm{wt} \%)$ \\
\hline $\mathrm{EP}+\mathrm{GF}$ & $\begin{array}{l}\text { Epoxy } \\
(45 \mathrm{wt} \%)\end{array}$ & $\begin{array}{l}\text { E-glass fabric } \\
(55 \mathrm{wt} \%)\end{array}$ & - \\
\hline $\mathrm{EP}+\mathrm{GF}+\mathrm{SL}$ & $\begin{array}{l}\text { Epoxy } \\
\text { (35wt\%) }\end{array}$ & $\begin{array}{l}\text { E-glass fabric } \\
(55 \mathrm{wt} \%)\end{array}$ & $\mathrm{MoS}_{2}(10 \mathrm{wt} \%)$ \\
\hline
\end{tabular}

present and cooled to ambient temperature. The required quantities of lubricant filler (10 wt\%) as calculated by the rule of mixtures were stirred gently into liquid epoxy resin, taking care to avoid the introduction of air bubbles. The resin filler mixture was degassed under vacuum for 2 hours. Hardener was then added to the resin in the ratio of $1: 10$ and then stirred to ensure complete mixing. The mixture was then poured into an open metallic mold coated with release agent to yield specimens of $200 \times 200 \times 3 \mathrm{~mm}$ upon curing and released from mold after 24 hours. Extreme care has been taken to avoid any undesirable filler settling effect by casting the slurry just prior to its gelling stage, all time keeping it in a stirred condition. This was done to ensure the uniform composition of cast specimens across its volume. Cast composites were postcured at $50^{\circ} \mathrm{C}$ for 2 hours.

2.2.2. Hand Lay-Up Technique. Composite laminates were prepared by dry hand lay-up method. The epoxy resin is mixed well with weighed amount $(10 \mathrm{wt} \%)$ of $\mathrm{MoS}_{2}$ particles. Hardener was added in the ratio of $1: 10$ and then stirred to ensure complete mixing. A releasing agent was applied on mold for easy removal of the composite stack and to obtain the accurate surface finish. The stacking procedure for preparing the laminate consists of placing the glass fabric one above the other with the resin mix well spread between the fabrics. A porous Teflon film was placed on the completed stack, and whole assembly was pressed between mold plates under a load of 0.5 MPa for 24 hours and allowed to cure under the room temperature. To ensure uniform thickness of sample, spacers of $3 \mathrm{~mm}$ were used between the mold plates. After demolding post curing was done at $120^{\circ} \mathrm{C}$ for 2 hours. Composite laminates without $\mathrm{MoS}_{2}$ particles were also prepared for comparison purpose. The laminate so prepared had dimension $250 \times 250 \times 3 \mathrm{~mm}$. Details of the fabricated composites are shown in Table 1 . Test specimens for the required dimensions were cut using a diamond-tipped cutter.

2.3. Mechanical Testing. Mechanical tests were performed at room temperature and as per ASTM standards. The standards used along with test specimen sizes are listed in Table 2. All the mechanical test results reported were calculated as averages over five specimens for each composition.

Densities of the composite were determined using the Archimedes principle. Hardness of developed composite samples was measured using Rockwell's Hardness Tester on M-Scale. The tensile tests and flexural tests were investigated
TABLE 2: ASTM standards and specimen size.

\begin{tabular}{lccc}
\hline Sl. no. & Property & Standard & Specimen size $(\mathrm{mm})$ \\
\hline 1 & Density & ASTM D792 & $20 \times 10 \times 3$ \\
2 & Hardness & ASTM D785 & $20 \times 20 \times 3$ \\
3 & Tensile & ASTM D3039 & $150 \times 12.5 \times 3$ \\
4 & Flexural & ASTM D790 & $90 \times 12.5 \times 3$ \\
5 & Abrasive wear & ASTM G99 & $10 \times 10 \times 3$ \\
\hline
\end{tabular}

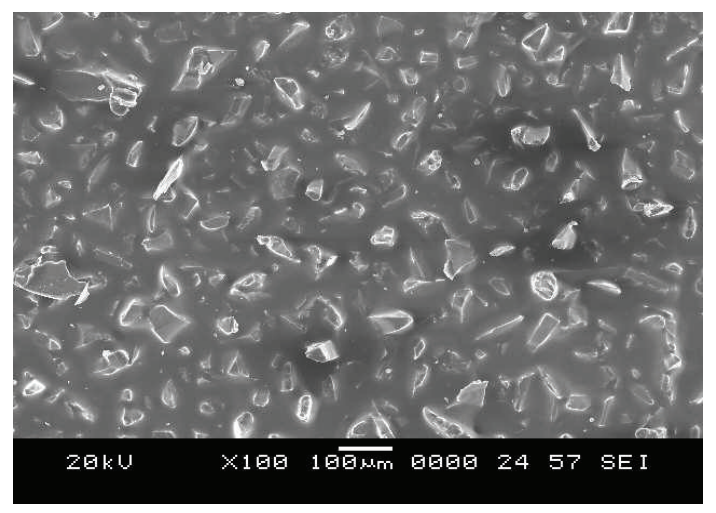

Figure 2: SEM image of SiC abrasive paper (400 grit size).

using Universal testing machine (JJ Lloyd, London, capacity $1-20 \mathrm{kN})$. These tests were performed at a cross-head speed of $2 \mathrm{~mm} / \mathrm{min}$ considering a gauge length of $50 \mathrm{~mm}$.

2.4. Abrasive Wear Test. Two-body abrasive wear studies were carried out on a pin-on-disc machine (Model TR $201 \mathrm{C}$, Ducom Instruments, Bangalore, India). A composite sample of size $10 \times 10 \times 3 \mathrm{~mm}$ was glued to a mild steel pin having a square cross-section of $10 \mathrm{~mm}$ and $50 \mathrm{~mm}$ lengths and was abraded against water proof 1200 grits silicon carbide (SiC) paper for uniform contact with the rotating disc. The specimen surface was then cleaned with acetone and dried. The pin along with the specimen was then weighed (Shimadzu, Japan, $0.1 \mathrm{mg}$ accuracy) followed by abrading the specimen against $\mathrm{SiC}$ paper of grit size 400 fixed on a disc rotating at $1 \mathrm{~m} / \mathrm{s}$. The range of applied load was $5-15 \mathrm{~N}$ and five abrading distances, namely, 60, 120, 180, 240, and $300 \mathrm{~m}$ under multipass condition. After cleaning with a blower to remove wear debris, the pin was reweighed to calculate weight loss. A minimum of three trials for each specimen was conducted to ensure repeatability of test data. The weight loss was converted into volume loss by using the measured density of the specimen. The specific wear rate $\left(K_{s}\right)$ was calculated using (1):

$$
K_{s}=\frac{\nabla V}{L \times d} \mathrm{~m}^{3} / \mathrm{Nm},
$$

where $\nabla V$ is the volume loss in $\mathrm{m}^{3}, L$ is the load in Newton and $d$ is the abrading distance in meters. The scanning electron microscopy photo of $\mathrm{SiC}$ abrasive paper of 400 grit size before the test is shown in Figure 2. 
TABLE 3: Density and hardness of test specimen.

\begin{tabular}{lcc}
\hline Sample code & Density $(\mathrm{g} / \mathrm{cc})$ & Rockwell hardness (M scale) \\
\hline EP & 1.198 & 77 \\
EP+SL & 1.221 & 80 \\
EP+GF & 1.487 & 90 \\
EP+GF+SL & 1.596 & 92 \\
\hline
\end{tabular}

2.5. SEM Observations. Worn surfaces of samples were observed by using scanning electron microscope (Joel JSM6380LA, Japan). The sample surfaces were gold coated (Joel JFC-1600, Auto fine coater, Japan) before observation. Worn microstructure of composites has been taken to study the effect of maximum load and maximum sliding distance on abrasive wear of composites.

\section{Results and Discussion}

\subsection{Mechanical Properties}

3.1.1. Density. Density is the simplest property which can be measured easily when a new type of composite material system is developed. Density values are shown in Table 3. The addition of $10 \mathrm{wt} \% \mathrm{MoS}_{2}$ particles $(5.16 \mathrm{~g} / \mathrm{cc}$ ) resulted in a slight increase in the density of neat epoxy. Further, with the reinforcement of the epoxy with E-glass fibers $(2.56 \mathrm{~g} / \mathrm{cc})$, the density value was increased notably. Among all the specimens tested, hybrid composite (EP+GF+SL) was found to have the highest density value. This increase in density of composites was mainly due to the high density of the $\mathrm{MoS}_{2}$ fillers and glass fibers.

3.1.2. Hardness. Hardness of a material denotes the resistance offered to the localized plastic deformation. The hardness test results are plotted in Table 3 . From the table, it can be observed that hardness of neat epoxy specimen slightly increases with addition of $\mathrm{MoS}_{2}$ filler. Thus, it can be seen that the incorporation of $\mathrm{MoS}_{2}$, which increased the density of neat epoxy, also contributed towards the improvement of hardness of neat epoxy. However, the addition of glass fibers greatly improved the hardness of neat epoxy as expected. It was also observed that $\mathrm{MoS}_{2}$ particles have slightly modified hardness of $\mathrm{EP}+\mathrm{GF}$ samples.

3.1.3. Tensile Properties. Tensile properties are listed in Table 4. It was observed that the addition of $10 \mathrm{wt} \%$. of the solid lubricant $\left(\mathrm{MoS}_{2}\right)$ reduced the tensile strength, tensile modulus and percentage elongation of neat epoxy by nearly $17 \%, 4 \%$, and $30 \%$, respectively. This was because the addition of $\mathrm{MoS}_{2}$ particles introduced large amount of stress concentration in the resin-filler mixture which led to discontinuities in the matrix in the form of microvoids which ultimately resulted in lowering the tensile properties. The large differences in the densities of the epoxy and $\mathrm{MoS}_{2}$ particles could be the reason for this kind of behaviour. Thus, the addition of $\mathrm{MoS}_{2}$ solid lubricant had a detrimental effect on the tensile properties of the neat epoxy. However,
TABLE 4: Tensile properties of test specimens.

\begin{tabular}{lcccc}
\hline & $\mathrm{EP}$ & $\mathrm{EP}+\mathrm{SL}$ & $\mathrm{EP}+\mathrm{GF}$ & $\mathrm{EP}+\mathrm{GF}+\mathrm{SL}$ \\
\hline $\begin{array}{l}\text { Tensile } \\
\text { strength }\end{array}$ & $58 \pm 2$ & $48 \pm 2$ & $258 \pm 3$ & $233 \pm 3$ \\
$S(\mathrm{MPa})$ & & & & \\
\hline $\begin{array}{l}\text { Tensile } \\
\text { modulus }\end{array}$ & $2.16 \pm 0.08$ & $2.08 \pm 0.06$ & $4.14 \pm 0.04$ & $3.95 \pm 0.04$ \\
$E(\mathrm{GPa})$ & & & & \\
\hline $\begin{array}{l}\text { Percentage } \\
\text { elongation } \\
e(\%)\end{array}$ & $3.45 \pm 0.07$ & $2.42 \pm 0.05$ & $8.74 \pm 0.10$ & $6.68 \pm 0.10$ \\
\hline
\end{tabular}

the reinforcement of the plain epoxy with only glass fiber mat resulted in a hike in the tensile strength, tensile modulus, and elongation by nearly an order of five, two, and three, respectively compared to that of neat epoxy. But with the addition of solid lubricant to epoxy-glass composites, the tensile properties were slightly reduced. Thus, from the experimental observation, it could be seen that the addition of solid lubricant $\left(\mathrm{MoS}_{2}\right)$ had no beneficiary effect on tensile properties of composites.

3.1.4. Flexural Properties. The experimental data on flexural testing is presented in Figure 3. It is clear that when epoxy was reinforced with the glass fibers, there was a tremendous increase in the flexural strength nearly four times than that of the neat epoxy sample. However, when $\mathrm{MoS}_{2}$ was used as filler in the neat epoxy and glass epoxy sample, there was a reduction in the flexural strength by $11 \%$ and $3 \%$, respectively. The factors that reduced the tensile strength also acted to reduce the flexural strength of the composites. Contrary to the variation of flexural strength, an interesting observation was made in case of flexural modulus. It was observed that the inclusion of $\mathrm{MoS}_{2}$ particles has acted to improve the flexural modulus of neat-epoxy and glass epoxy test samples by nearly $8 \%$ and $32 \%$, respectively. This trend indicated better stress transfer between the matrix and reinforcement under bending load. The significant increase in flexural modulus with the addition of the lubricating filler to the glass-epoxy composites could possibly be due to synergism between polymer matrix and solid lubricant where lubricant does not interfere with the stress transfer role of the polymer matrix especially under flexural loading conditions [14].

Lancaster [15] pointed out that even with reinforcing fibers, the increase in stiffness of a composite may be greater than the increase in strength. For particulate fillers, there is generally a greater increase in stiffness (i.e. modulus) than in structural strength. This is particularly true for solid lubricant particles, where because of their easy shear properties, they will not generally increase the strength and will sometimes reduce it. In the present study, the results are in accordance with these reported trends. The experimental aspects related to the voids and/or pores which strongly affect the mechanical properties of brittle materials such as thermoset polymer like the epoxy resin used here are mainly responsible for the deterioration in the mechanical properties. This phenomenon of reduction in mechanical 


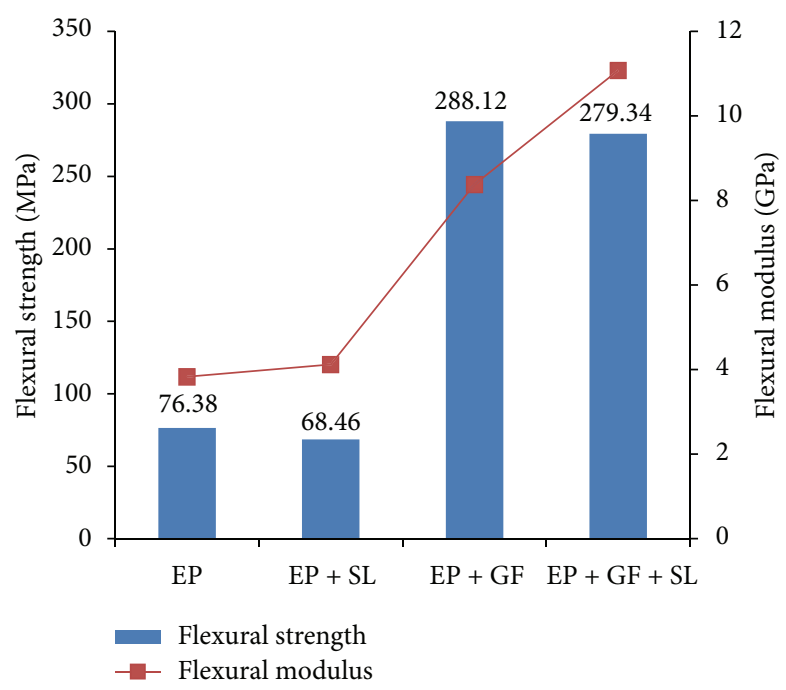

FIGURE 3: Flexural properties of different test specimens.

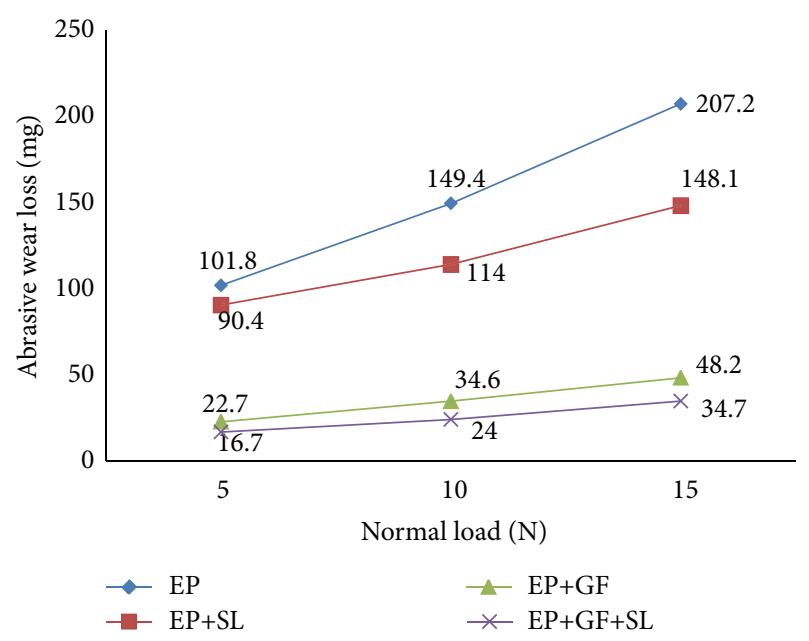

Figure 4: Abrasive wear loss of test specimens at different loads.

properties of polymer composites with addition of solid lubricant was also noticed by earlier researchers $[7,8,16]$. Further investigation is, however, warranted to verify the lubricant effects on mechanical properties at lower loadings.

\subsection{Abrasive Wear Properties}

3.2.1. Abrasive Wear Loss. The measured wear loss values for different loads and test specimens are presented in Figure 4. Neat epoxy sample exhibited the maximum wear loss during the test as compared to the rest of the samples. But it was possible to bring down this value of wear loss with the addition of solid lubricant $\left(\mathrm{MoS}_{2}\right)$. Further reduction in wear loss was recorded when the epoxy specimen was reinforced with the glass fibers. The hybrid composite $(\mathrm{EP}+\mathrm{GF}+\mathrm{SL})$ exhibited the minimum wear loss among the rest of the samples. The observed wear loss trend for the filled EP +GF composite is in line with the results reported elsewhere [17].

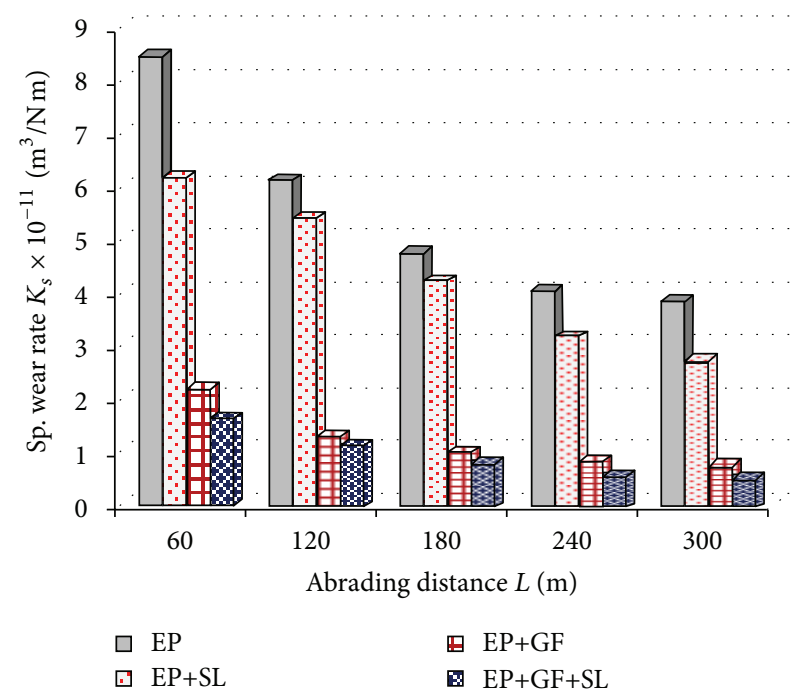

FIGURE 5: Specific wear rate versus sliding distance for different test specimens.

Another important observation was that wear loss increased with the increase in the applied normal load in case of all the specimens. With the increased load, the incorporated filler in the composite may become loosened owing to the wear of matrix material and detach itself from the system leading to higher wear loss [18]. However, the presence of the solid lubricant $\left(\mathrm{MoS}_{2}\right)$ could reduce the rate of increase of wear loss with the increase in the applied load. Thus, it could be noted that at high loads, the presence of the solid lubricant could bring down the wear loss to a large extent in comparison with the specimens without the solid lubricant.

Wear loss observed was lower for specimens with solid lubricant particles. $\mathrm{MoS}_{2}$ has a hexagonal crystal structure with the intrinsic property of easy shear [19], and these particles act as an effective barrier for large-scale deformation of epoxy matrix material. The wear loss of the different test specimens follows the sequence: $\mathrm{EP}>\mathrm{EP}+\mathrm{SL}>\mathrm{EP}+\mathrm{GF}>\mathrm{EP}+\mathrm{GF}+\mathrm{SL}$.

3.2.2. Specific Wear Rate $\left(K_{s}\right)$. The plot of specific wear rate versus abrading distance of composites at a constant load of $15 \mathrm{~N}$ is presented in Figure 5. It is clear that specific wear rate decreased considerably with the increase in the sliding distance. The reason is that with the increase in abrading distance, some of the worn particles clog the abrasive paper and hence slows down the further wear. The reinforcement of glass fibers has reduced the wear rate of $\mathrm{EP}$ and $\mathrm{EP}+\mathrm{SL}$ composites by an order of magnitude of four and three, respectively, after an abrading distance of $60 \mathrm{~m}$. This is due to the fact that fibers have high hardness values and thus better resistance against abrasion. Thus, the rate at which material is removed decreases after glass fiber reinforcement as expected. The plot also reveals the effective role of $\mathrm{MoS}_{2}$ particles in bringing down the wear rate of $\mathrm{EP}$ and $\mathrm{EP}+\mathrm{GF}$ composites. The obtained specific wear rate values are in agreement with the findings reported in the literature [20,21]. 


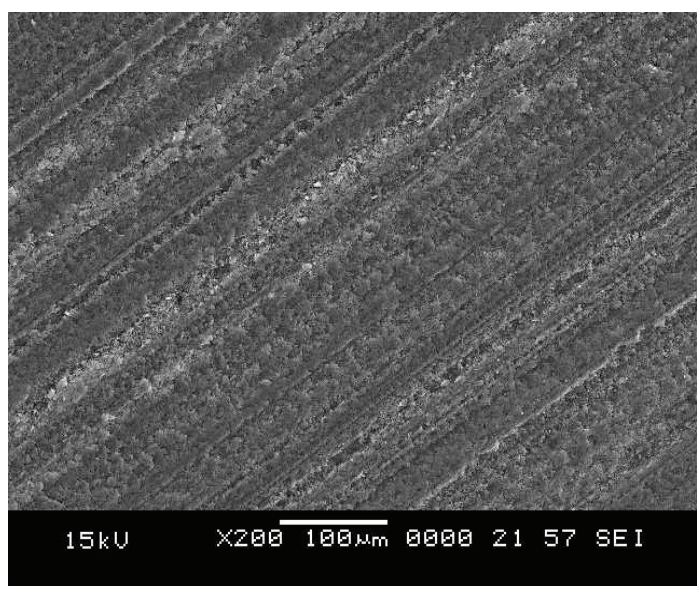

(a)

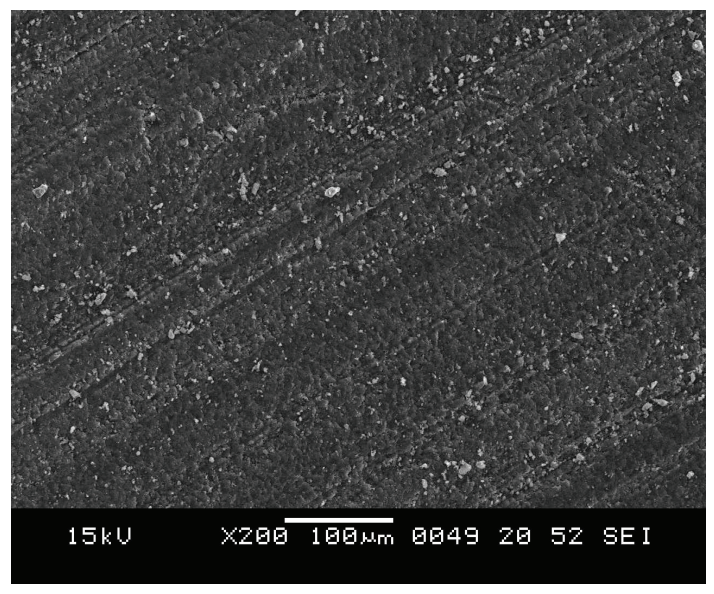

(b)

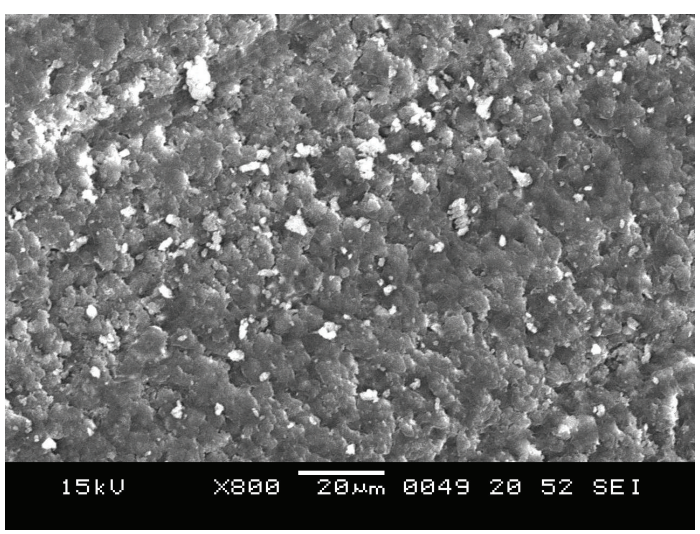

(c)

FIGURE 6: Worn microstructure of composites (a) (×200) EP specimen, (b) $(\times 200)$ and (c) $(\times 800)$ EP+SL specimen (test condition: load 15 N, sliding distance $300 \mathrm{~m}$ ).

This result clearly indicates that the specific wear rate depends on abrading distances.

The literature on the correlation studies on the fiberreinforced composites indicates that, generally, the abrasive wear performance is directly related to $S e$ factor where $S$ is the ultimate tensile strength and $e$ is the elongation to break [22]. Various other factors such as $S, e, H$ (hardness), HSe, and $S^{2} e$ are also reported to be responsible for controlling the wear performance [23]. In the fabric-reinforced composites selected in this work, however, these properties could play hardly any role in controlling the wear. The Se factor or HSe factor is the highest for EP+GF composites (Table 4), while its performance was not the best.

3.2.3. Worn Surface Morphology. In general, it was observed that the major wear mechanisms responsible for abrasive wear are microploughing, microcracking, and microcutting [24]. Figures 6(a) and 6(b) show the worn surface morphology of EP and EP+SL composites under $15 \mathrm{~N}$ load after $300 \mathrm{~m}$ sliding distance and under multipass abrasive wear condition. From these micrographs, one can observe that EP specimen exhibits slightly rougher worn surface compared to EP+SL composite. This clearly indicates the wear resistance property imparted by lubricant particles. Wear tracks are formed during multipass wear due to micro-cutting. It is clear from the magnified image (Figure 6(c)) that initially microcracks were formed around $\mathrm{MoS}_{2}$ particles, and particles were removed under compression and shear. Wear track consisted of wear debris which included loose matrix material and $\mathrm{MoS}_{2}$ particles. Figure 6(c) displays wear debris formation. Small round particles of $3-4 \mu \mathrm{m}$ in the micrograph could be $\mathrm{MoS}_{2}$ particles.

Figure 7(a) illustrates SEM picture of EP+GF composite for $15 \mathrm{~N}$ load and $300 \mathrm{~m}$ sliding distance. Formation of wear debris, adherence of the debris on fibers, and breakage of fibers are the important wear mechanisms which could be observed from picture. Interface separation between matrix and the fiber can also be seen. Figure 7(b) illustrates SEM picture of $\mathrm{EP}+\mathrm{GF}+\mathrm{SL}$ composite for $15 \mathrm{~N}$ load and $300 \mathrm{~m}$ sliding distance. Overall surface was smoother than the previous one, though the wear behavior is almost similar. This could be because of $\mathrm{MoS}_{2}$ film formed between the composite and counterface. The EP+GF+SL composite suffered lowest damage and wear during tribo-tests. The observed mechanisms support measured values of wear loss for $15 \mathrm{~N}$ load. Figure has evidenced micro-cracking, chip 


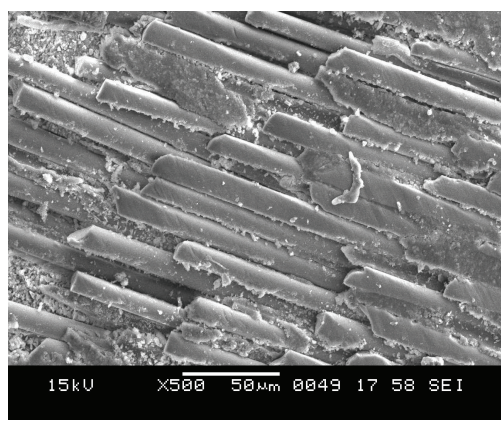

(a)

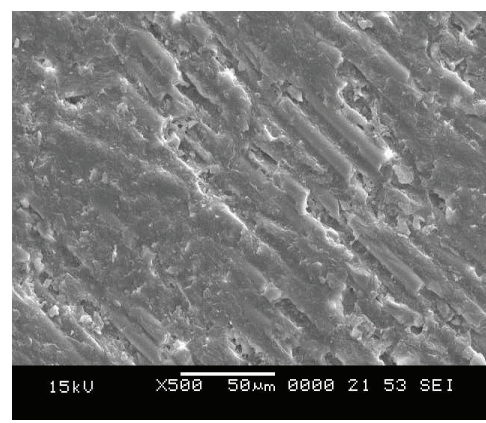

(b)

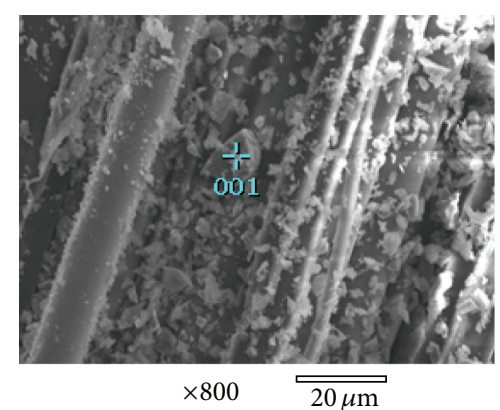

(c)

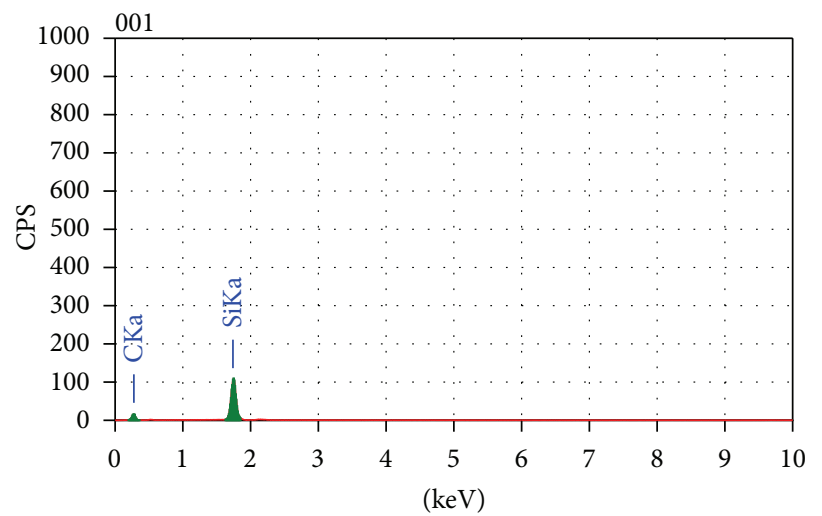

(d)

FIGURE 7: Worn microstructure of composites (a) (×500) EP+GF specimen, (b) (×500) EP+GF+SL specimen and (c) $(\times 800)$ EP+GF specimen (Test condition: Load $15 \mathrm{~N}$, sliding distance $300 \mathrm{~m}$ ), (d) EDAX spectrum confirming the presence of SiC particle embedment into EP+GF composite.

formation, exposure of fibers, and less fiber breakage. Less damage to matrix and embedded fiber is mainly due to the presence of $\mathrm{MoS}_{2}$ particles acting as antiwear additive and hence retard wear loss. A very rare worn surface morphology observed is back transfer of counterface material ( $\mathrm{SiC}$ particles) into composite surface. $\mathrm{SiC}$ abrasive particles from the emery paper penetrated into composite specimens are clearly seen in higher magnification image of $\mathrm{EP}+\mathrm{GF}$ composites (Figure 7(c)). In this figure, matrix fracture due to cutting action of abrasives is apparent, and extent of damage to the matrix and fiber is severe. Spot analysis of this embedded particle using EDAX has shown peaks of carbon (C) and silicon $(\mathrm{Si})$ as indicated in Figure 7(c). This EDAX spectrum confirms the particle embedment effect in EP+GF composite.

\section{Conclusion}

Epoxy, an excellent engineering thermoset plastic, and its composite were evaluated for mechanical and abrasive wear performance. The composites were of three types: first epoxy with $\mathrm{MoS}_{2}$ particles; second epoxy with glass fibers; and third epoxy with glass fibers and $\mathrm{MoS}_{2}$ particles. The solid lubricants and fibers play a vital role in influencing the performance of neat polymer in a beneficial manner. Solid lubricant, namely, $\mathrm{MoS}_{2}$ was proved to be beneficial in abrasive wear mode, and, acted to deteriorate the mechanical performance. SEM studies were proved useful in analyzing wear mechanisms and correlating wear performance.

\section{Acknowledgments}

The authors would like to thank the Director, Principal, Viceprincipal and Head of Mechanical Engineering, St. Joseph Engineering College, Mangalore, India, for encouragement to carry out this research work. The authors also extend their thanks to M/s. Brakes India, Mysore, for providing testing facilities, NITK Surathkal, India, for SEM facilities, and GTTC Mangalore, India, for the technical support.

\section{References}

[1] K. Friedrich, S. Fakirov, and Z. Zhang, Polymer Composites: From Nano- to Macro-Scale, Springer, New York, NY, USA, 2005.

[2] P. K. Mallick, Fiber Reinforced Composites: Materials, Manufacturing and Design, Marcel Dekker, New York, NY, USA, 3rd edition, 2007.

[3] H. Unal, U. Sen, and A. Mimaroglu, "Abrasive wear behaviour of polymeric materials," Materials and Design, vol. 26, no. 8, pp. 705-710, 2005.

[4] V. Pettarin, M. J. Churruca, D. Felhös, J. Karger-Kocsis, and P. M. Frontini, "Changes in tribological performance of high molecular weight high density polyethylene induced by 
the addition of molybdenum disulphide particles," Wear, vol. 269, no. 1-2, pp. 31-45, 2010.

[5] O. Jacobs, R. Jaskulka, F. Yang, and W. Wu, "Sliding wear of epoxy compounds against different counterparts under dry and aqueous conditions," Wear, vol. 256, no. 1-2, pp. 9-15, 2004.

[6] X. Zhang, G. Liao, Q. Jin, X. Feng, and X. Jian, "On dry sliding friction and wear behavior of PPESK filled with PTFE and graphite," Tribology International, vol. 41, no. 3, pp. 195-201, 2008.

[7] X. Li, Y. Gao, J. Xing, Y. Wang, and L. Fang, "Wear reduction mechanism of graphite and $\mathrm{MoS}_{2}$ in epoxy composites," Wear, vol. 257, no. 3-4, pp. 279-283, 2004.

[8] X. R. Zhang, X. Q. Pei, and Q. H. Wang, "Tribological properties of $\mathrm{MoS}_{2}$ and carbon fiber reinforced polyimide composites," Journal of Materials Science, vol. 43, no. 13, pp. 4567-4572, 2008.

[9] Kishore, P. Sampathkumaran, S. Seetharamu, P. Thomas, and M. Janardhana, "A study on the effect of the type and content of filler in epoxy-glass composite system on the friction and slide wear characteristics," Wear, vol. 259, no. 1-6, pp. 634-641, 2005.

[10] B. Suresha, G. Chandramohan, P. Samapthkumaran, and S. Seetharamu, "Investigation of the friction and wear behavior of glass-epoxy composite with and without graphite filler," Journal of Reinforced Plastics and Composites, vol. 26, no. 1, pp. 81-93, 2007.

[11] J. Wang, M. Gu, and B. S. S. Ge, "Investigation of the influence of $\mathrm{MoS}_{2}$ on the tribological properties of carbon fiber reinforced Nylon 1010 composites," Wear, vol. 255, no. 1-6, pp. 774-779, 2003.

[12] J. Bijwe, J. J. Rajesh, A. Jeyakumar, A. Ghosh, and U. S. Tewari, "Influence of solid lubricants and fibre reinforcement on wear behaviour of polyethersulphone," Tribology International, vol. 33, no. 10, pp. 697-706, 2000.

[13] X. R. Zhang, X. Q. Pei, and Q. H. Wang, "Friction and wear studies of polyimide composites filled with short carbon fibers and graphite and micro $\mathrm{SiO}_{2}, "$ Materials and Design, vol. 30, no. 10, pp. 4414-4420, 2009.

[14] K. B. Adhikary, C. B. Park, M. R. Islam, and G. M. Rizvi, "Effects of lubricant content on extrusion processing and mechanical properties of wood flour-high-density polyethylene composites," Journal of Thermoplastic Composite Materials, vol. 24, no. 2, pp. 151-177, 2011.

[15] J. K. Lancaster, "Polymer-based bearing materials. The role of fillers and fibre reinforcement," Tribology, vol. 5, no. 6, pp. 249255, 1972.

[16] A. Bolvari, S. Glenn, R. Janssen, and C. Ellis, "Wear and friction of aramid fiber and polytetrafluoroethylene filled composites," Wear, vol. 203-204, pp. 697-702, 1997.

[17] B. Suresha, G. Chandramohan, P. R. S. Rao, P. Sampathkumaran, and S. Seetharamu, "Influence of SiC filler on mechanical and tribological behavior of glass fabric reinforced epoxy composite systems," Journal of Reinforced Plastics and Composites, vol. 26, no. 6, pp. 565-578, 2007.

[18] Kishore, P. Sampathkumaran, S. Seetharamu, S. Vynatheya, A. Murali, and R. K. Kumar, "SEM observations of the effects of velocity and load on the sliding wear characteristics of glass fabric-epoxy composites with different fillers," Wear, vol. 237, no. 1, pp. 20-27, 2000.

[19] A. R. Lansdown, Molybdenum Disulphide Lubrication, Tribology Series 35: Editor- Dowson, Elsevier, Amsterdam, The Netherlands, 1999.
[20] B. N. Ravi Kumar, B. Suresha, and M. Venkataramareddy, "Effect of particulate fillers on mechanical and abrasive wear behaviour of polyamide 66/polypropylene nanocomposites," Materials and Design, vol. 30, no. 9, pp. 3852-3858, 2009.

[21] B. M. Sole and A. Ball, "On the abrasive wear behaviour of mineral filled polypropylene," Tribology International, vol. 29, no. 6 , pp. 457-465, 1996.

[22] J. K. Lancaster, "Friction and wear in polymer science," in $A$ Material Science Handbook, A. D. Jenkins, Ed., pp. 959-1046, North-Holland, Amsterdam, The Netherlands, 1972.

[23] J. J. Rajesh, J. Bijwe, and U. S. Tewari, "Influence of fillers on abrasive wear of short glass fibre reinforced polyamide composites," Journal of Materials Science, vol. 36, no. 2, pp. 351356, 2001.

[24] G. W. Stachowiak and A. W. Batchelor, Engineering Tribology, Butterworth-Heinemann, Oxford, UK, 2nd edition, 2001. 

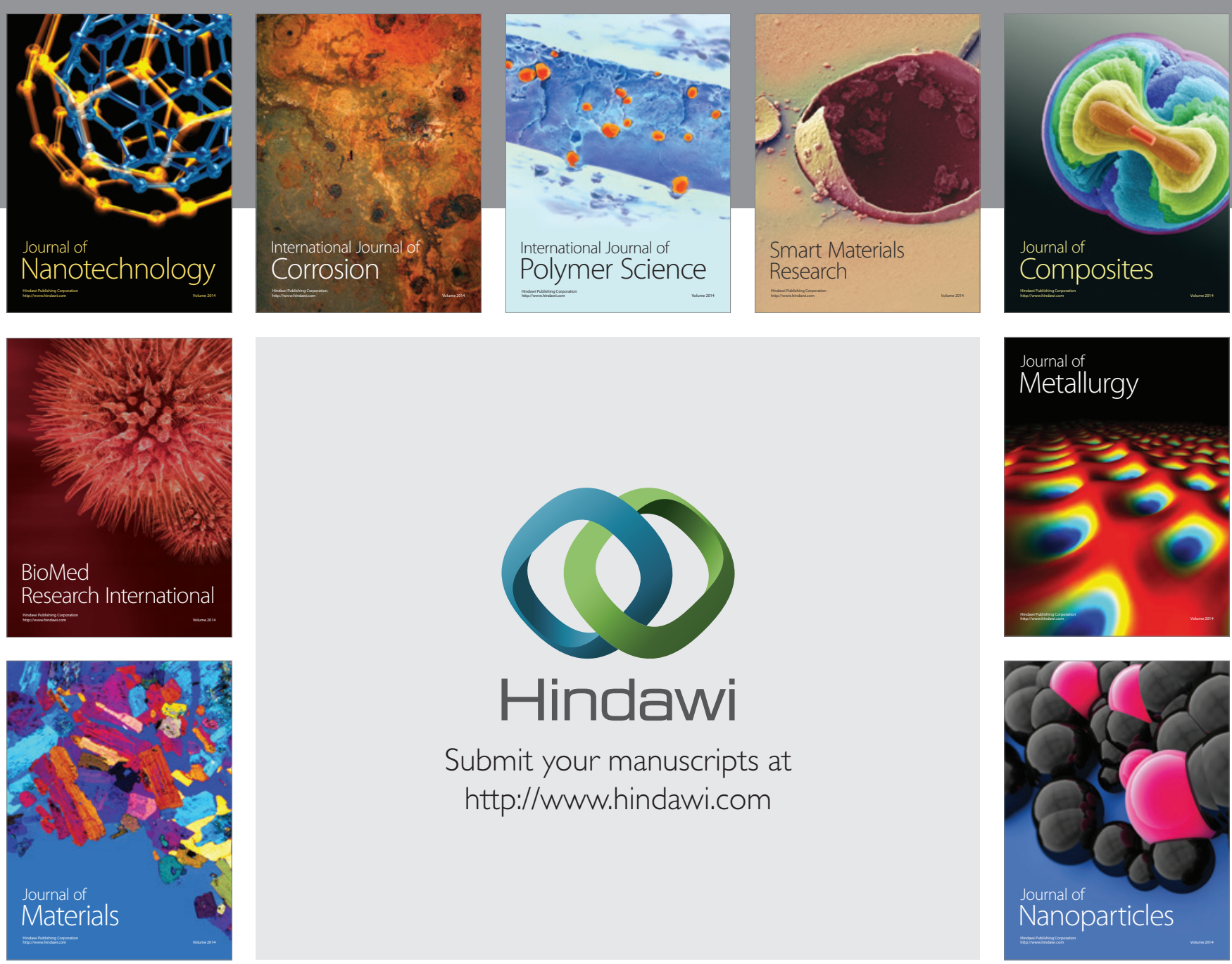

Submit your manuscripts at http://www.hindawi.com
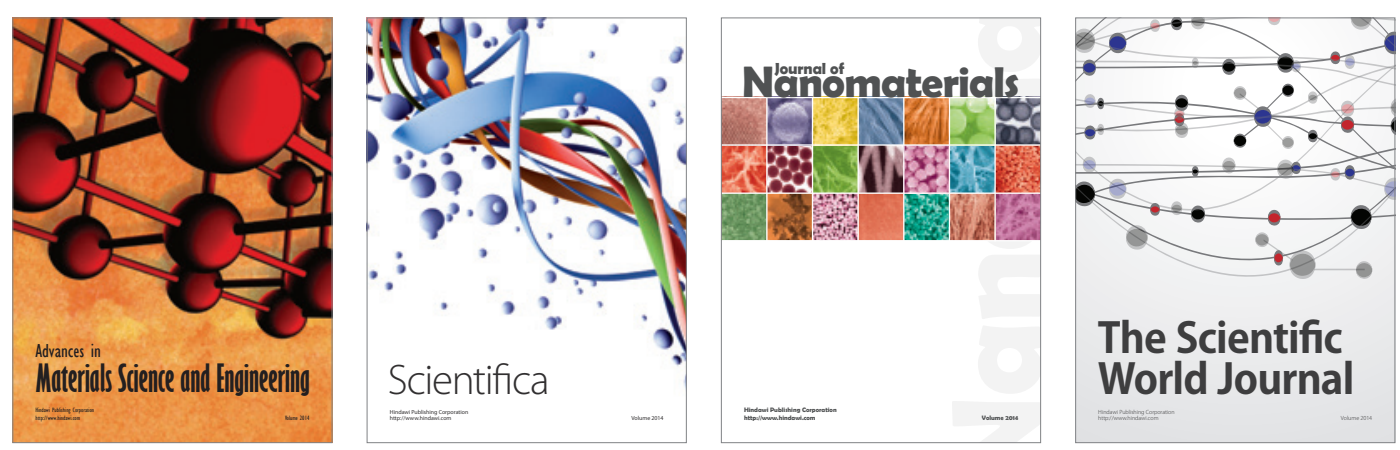

\section{The Scientific World Journal}
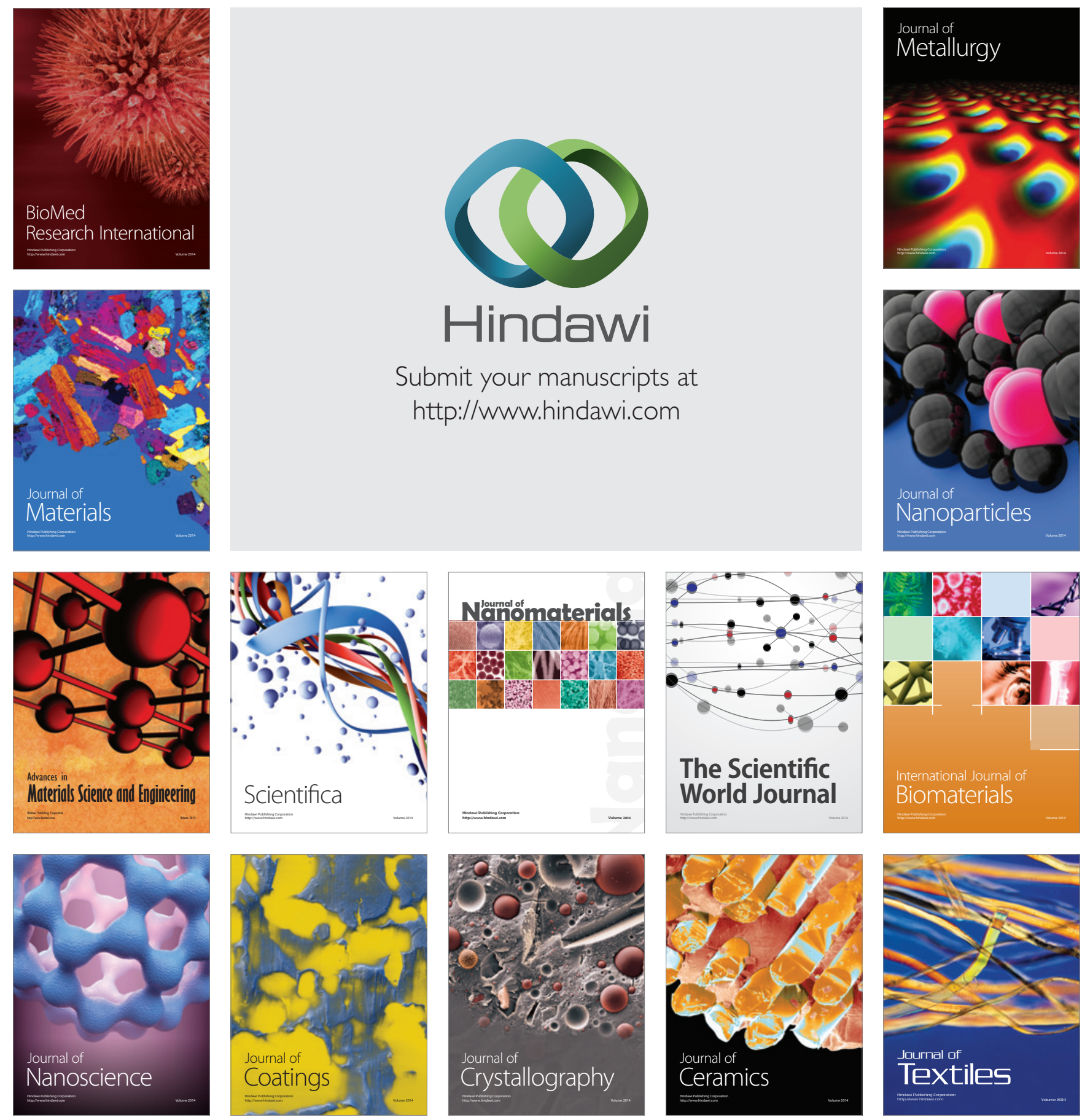